\title{
Microclimate Data For Building Energy Modelling: Study On ENVI-Met Forcing Data
}

\author{
Agnese Salvati ${ }^{1}$, Maria Kolokotroni ${ }^{1}$ \\ ${ }^{1}$ Brunel University London, London, United Kingdom
}

\begin{abstract}
ENVI-met iswidely used for urban microclimate simulations. However, the evaluation studies published so far show a wide variation of its accuracy. This paper investigates the ENVI-met accuracy for varying settings of (a) the meteorological forcing conditions, (b) input area size and (c) modelling detail. The model's accuracy is assessed using air temperature measurements of an urban canyon in London, UK. The results show that the impact of the hourly air temperature and average wind speed values used to force the simulation is very important. The Urban Weather Generator has proved suitable for generating forcing urban air temperatures when measurements are not available.
\end{abstract}

\section{Introduction}

The ENVI-met model is a microclimate simulator for urban areas with high spatial and temporal resolution. The model is widely used for assessing the effectiveness of urban temperature mitigation strategies, but the many evaluation studies published so far report a significant range of variability of its accuracy on air temperature estimations, with RMSE (Root mean squared error) ranging between $0.66 \mathrm{~K}$ to $5.5 \mathrm{~K}$ (Salata at al. 2016).

The hypothesis of this study is that ENVI-met accuracy may vary substantially depending on the forcing conditions used for the simulation and, in particular, the meteorological conditions.

ENVI-met estimations are based on a three-dimensional CFD atmospheric model (3D model) forced by a onedimension model (1D model) providing the vertical profile of air temperature, relative humidity, wind speed and direction at the inflow boundary of the 3D model (Bruse, 2018). Therefore, the values assigned to the 1D model are crucial on the results of the 3D model.

The relationship between the $1 \mathrm{D}$ and the 3D models can be read in terms of urban physics as the relationship between the local urban climate and the microclimate of specific urban spaces. The local urban climate is determined by the average characteristics of the urban fabric such as land cover, building density and urban metabolism for areas up to $1 \mathrm{Km}$ length; (Kolokotroni et al., 2008; Stewart and Oke, 2012; Oke et al., 2017; Salvati et al., 2017; Palme et al., 2018;). Therefore, the local urban climate represents the boundary condition to the individual microclimates of specific urban street canyons, plazas, squares, gardens of an urban area. The microscale climate variability is expected to be more or less significant according to the morphology homogeneity of the area.

In light of this, the local climate determined by neighbourhood characteristics should be used as forcing conditions to microclimate simulations with ENVI-met. On-site air temperature measurements and climate data from local urban weather stations can be used for this scope, when possible. When measurements are not available, the local urban climate can be estimated using validated urban energy balance models (Bueno et al., 2013; Salvati et al, 2016; Lindberg et al., 2018; Mao 2018) which are designed to estimate local climates across a city.

This study provides a scientific methodology to choose appropriate boundary conditions for reliable microclimate simulations. In particular, it shows how to identify the correct temperature and wind speed data to force the simulation and how to model the area in terms of size, materials and vegetation details in order to improve the accuracy of the microclimate simulation. A discussion on the impact of local scale and micro scale climate variabilities on building energy demand is also provided.

\section{Methods}

A residential area of London (UK) is used as a case study to investigate the impact of significant input parameters of ENVI-met ( $\mathrm{v}$ 4.3.2) on the accuracy of the microclimate results. The ENVI-met accuracy is evaluated against hourly air temperature measurements taken at $5 \mathrm{~m}$ agl (above ground level) in an urban canyon of the study area (Figure 1). The hourly air temperatures were recorded over the period 2006-2007. The hottest day of observation, the $5^{\text {th }}$ of August 2007, was used to calibrate the model and to assess its accuracy. The air temperature at $5 \mathrm{~m}$ height is deemed a suitable variable to calibrate the ENVI-met model being a bulk index of the local climate of an urban area, less likely to vary within a microscale domain compared to other variables such as near ground measurements, surface temperatures or wind speeds.

The parameters tested in the calibration process are the meteorological forcing data (wind speed and direction, air temperature and humidity), the source area size and the modelling detail in terms of materials and vegetation. The performance of the model is assessed by root mean squared error, square correlation coefficient and index of agreement (Maleki et al 2014) between the estimated and the observed hourly air temperatures. 

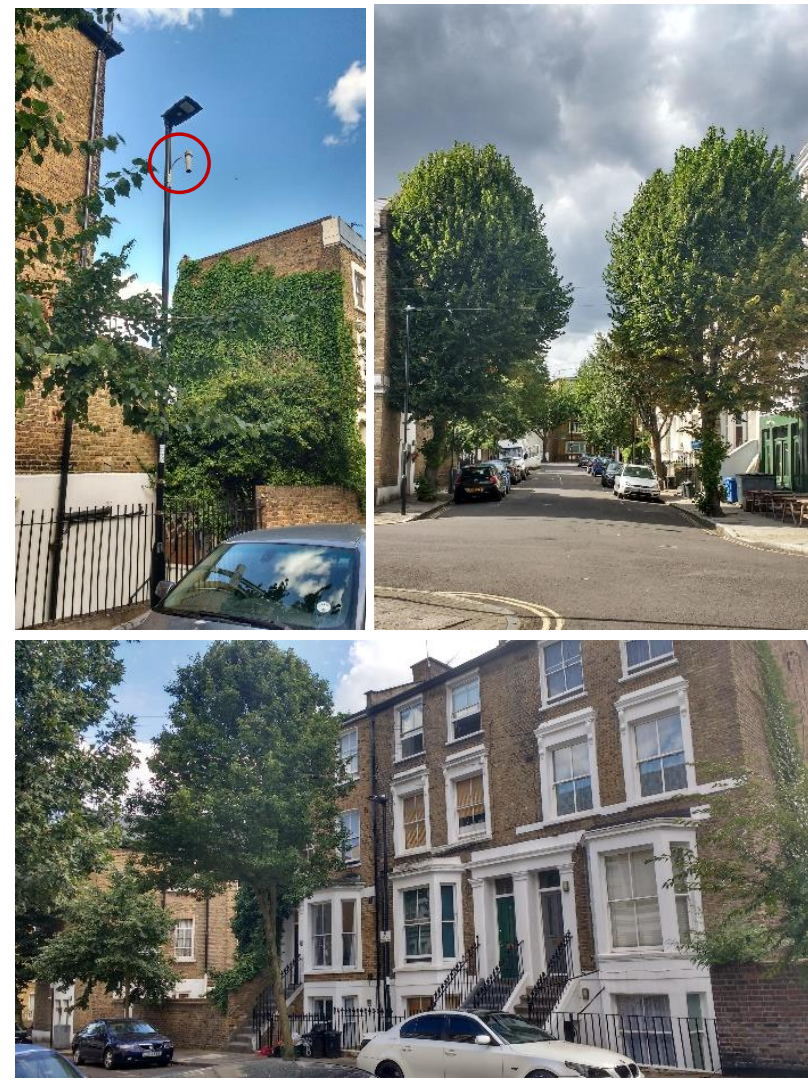

Figure 1: Air Temperature sensor location and pictures of the urban canyon

\section{Simulation starting day}

ENVI-met simulation starts at a specific time and day of the year and runs for the number of hours set in the configuration file.

It is commonly agreed that the starting time should be set at sunrise, so that the model can warm up fast. It is also known that a buffer time is needed for the model to stabilize, which is advised to be as long as 24-48 hrs (Goldberg et al. 2013; Durarte et al. 2015). The impact on the results of a $48 \mathrm{hrs}$ against $24 \mathrm{hrs}$ buffer time is tested in this study.

Different starting days have also been tested: the day chosen for comparison with the actual measurements (5th of August 2007) and the day before. In both cases, a 24 hrs buffer time was considered for the analyses of the result. The wind speed and direction and the air temperature and humidity corresponding to the two starting days were changed accordingly.

\section{Initial meteorological conditions}

The initial meteorological conditions to force ENVI-met simulations are the wind speed and direction measured at $10 \mathrm{~m} \mathrm{agl}$ and the air temperature and relative humidity at $2 \mathrm{~m}$ agl. The version 4.3.2 of ENVI-met allows simple forcing using hourly air temperature and relative humidity data, while wind speed and direction are considered constant over the $24 \mathrm{~h}$ cycle. The possibility to use diurnal cycles of air temperature and humidity to force simulations has proved to increase a lot the accuracy of results (Maleki et al. 2014). However, site-specific hourly climate data are not always available, especially for urban areas. For this reason, the possibility of using other meteorological datasets to obtain reliable results with ENVI-met is investigated in this study.

Three sets of temperature and humidity data have been tested: 1) the hourly air temperature and relative humidity data from the Heathrow airport meteorological station, 2) the air temperatures measurements at $5 \mathrm{~m}$ height in the study area and 3) the urban canopy air temperature data generated with the UWG v4 (Bueno et al. 2013; Mao et al. 2018). UWG calculates the local UHI intensity of an urban area and generates neighbourhood-specific hourly weather files starting from the weather data of meteorological stations located outside the city and a parametric description of the area of interest. The neighbourhood-averaged results of UWG can thus be used to force the detailed CFD simulation with ENVImet.

As for the wind forcing conditions, different methodologies have been proposed to calculate the speed attenuation in urban areas from measurements in open-flat fields. Two methodologies have been tested in this study: the coefficients of attenuation proposed by Kofoed \& Gaardsted (2004) and the power low wind profile equation proposed by the British Standards BS 5925:1991 on the principles and design for natural ventilation in buildings (B.S.I., 1991). Kofoed \& Gaardsted provided a table of coefficients to calculate the wind speed at datum height in an urban or suburban area from the wind speed at $10 \mathrm{~m}$ height in open flat areas. The BS proposes instead the use of the following power law equation:

$$
\mathrm{V}_{\mathrm{u}} / \mathrm{V}_{\mathrm{m}}=\alpha \mathrm{z}^{\gamma}
$$

where $\mathrm{z}$ is the datum height $(\mathrm{m})$ in the urban area, $\mathrm{V}_{\mathrm{u}}$ is the urban wind speed $(\mathrm{m} / \mathrm{s})$ at datum height, $V_{m}$ is the wind speed at the meteorological station $(\mathrm{m} / \mathrm{s})$ and $\alpha$ and $\gamma$ are coefficients depending on terrain roughness, which have been reported in Table 1 .

Table 1: Terrain coefficients for use with Equation (1)

\begin{tabular}{|c|c|c|}
\hline Terrain coefficient & $\boldsymbol{\alpha}$ & $\boldsymbol{\gamma}$ \\
\hline Open, flat & 0.68 & 0.17 \\
\hline Country with scattered wind breaks & 0.52 & 0.20 \\
\hline Urban & 0.35 & 0.25 \\
\hline City & 0.21 & 0.33 \\
\hline
\end{tabular}

The urban attenuation of wind speed in the case study area, considered as 'urban' as for the coefficients to apply, are reported in Table 2.

\section{Source area size and model detail}

Another crucial variable for ENVI-met simulation is the identification of the adequate source area size, depending on the objective of the analysis. In this regard, a wide variation can be found in literature, from input areas of $50 \times 50 \mathrm{~m}$ up to more than $1 \mathrm{Kmx} 1 \mathrm{Km}$, with different resolutions of the cells size, from $1 \mathrm{~m}$ to $7 \mathrm{~m}$. It has to be noted that this choice also depend on the version of the software; the free version is limited to an horizontal domain of 100x100 grids, while the licenced version has no limits. For this reason, one of the model sizes tested in this study correspond to a $100 \times 100$ grid with $2 \mathrm{~m}$ resolution, corresponding to an area of $200 \times 200 \mathrm{~m}$. 
The second size tested is bigger: a 250x150 grid of same resolution, corresponding to a 500x300m area. The large area correspond to the so-called source area of the temperature sensor in the point of measurement, as defined by Stewart and Oke (2012, p1891, fig 5). This means that the large area is not centred in the measurement point, but it is displaced toward the upwind direction, namely the same wind direction set in the initial meteorological conditions. The two areas and the corresponding ENVI-met models are reported in Figure $2 \mathrm{a}$ and $\mathrm{b}$.
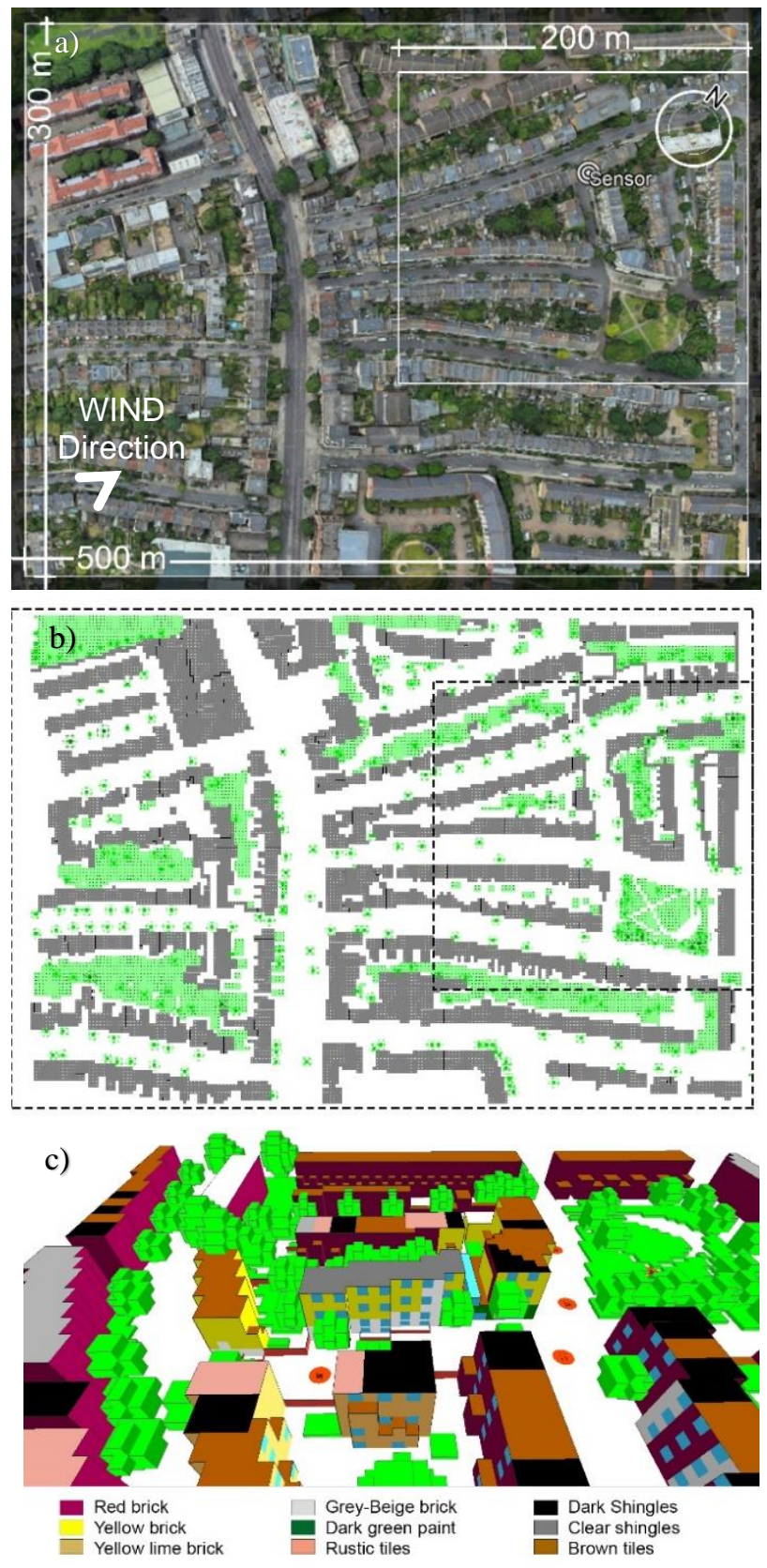

Figure 2: a) Urban areas corresponding to the small and large input area size, b) corresponding ENVI-met models, c) Zoom of the detailed 3D model

The version 4 of ENVI-met also added the possibility to model the spatial distribution of materials of facades and roofs. Therefore, a model in 3D-detailed mode was created and individual materials were assigned to the facades and roofs, as shown in Figure 2c. It has to be highlighted that the reproduction of the real distribution of materials was limited by the choice of the grid size of $2 \mathrm{~m}$. The distribution of material was gathered through site surveys and google earth visualizations. New materials were added to the ENVI-met database, setting reflectivity and emissivity values according to the London Urban Micromet data Archive - LUMA - developed by Kotthaus et al. (2014) and using digital photography techniques for those not present in the archive. The properties of materials used are reported in table 2.

Table 2:Model materials and properties

\begin{tabular}{|c|c|c|}
\hline Material & Reflectivity & Emissivity \\
\hline \multicolumn{3}{|l|}{ Walls } \\
\hline Red Brick & 0.32 & 0.95 \\
\hline Yellow brick & 0.43 & 0.94 \\
\hline Yellow lime brick & 0.31 & 0.91 \\
\hline Grey/beige brick & 0.53 & 0.93 \\
\hline White painted brick & 0.56 & 0.95 \\
\hline Dark green paint & $0.12 *$ & $0.9 * *$ \\
\hline Black paint & $0.08 *$ & $0.9 * *$ \\
\hline \multicolumn{3}{|l|}{ Roofs } \\
\hline Brown tiles & 0.2 & 0.93 \\
\hline Rustic tiles & 0.32 & 0.91 \\
\hline Black Shingles & 0.09 & 0.9 \\
\hline Clear shingles & 0.14 & 0.93 \\
\hline \multicolumn{3}{|l|}{ Pavements } \\
\hline Road asphalt & $0.19 *$ & $0.9 * *$ \\
\hline concrete pavement & $0.29 *$ & $0.9 * *$ \\
\hline courtyards pavement & $0.26^{*}$ & $0.9 * *$ \\
\hline
\end{tabular}

\section{Simulation of radiation environment}

Another improvement of the version 4 of ENVI-met regards the possibility to model the radiation fluxes in detail, using the 'Advanced Radiation Transfer Scheme' IVS (Indexed View Sphere). The IVS method allows modelling multiple interactions between surfaces, considering the actual state of each element instead of averaged values for incoming shortwave and longwave radiation and reflections (Bruse, 2018). The impact of this algorithm on results is also analysed.

\section{Results}

The results confirmed a determining influence of the forcing conditions on ENVI-met accuracy. For different input values of the tested parameters, the RMSE between the model estimations and the actual measurements varied from $5.42{ }^{\circ} \mathrm{C}$ to $1.15^{\circ} \mathrm{C}$, as reported in Table 4 .

The results clearly indicate that the model is reliable only for the day of the forcing conditions, in spite of the starting date and the simulation time settings. The choice of different reference days for the meteorological starting conditions caused the decrease of the RMSE from 5.42$3.51{ }^{\circ} \mathrm{C}$ in S01-03 to much better accuracies in all the other runs. This is explained by the fact that the $3 \mathrm{D}$ model of ENVI-met solves the fluid motion equations given the inflow boundary conditions provided by the 1D model. Using simple forcing, the boundary conditions are a 24hours cycle of air temperature and humidity with constant wind speed and direction (ENVI-met v 4.3.2). 
For this reason, the results are reliable only for the day used to set the forcing conditions. However, this issue has been already overcome with the last releases of the software such as the ENVI-met 4.4 Winter 1819 that enabled full meteorological forcing including air temperature and humidity, solar radiation, wind speed and direction for longer meteorological periods.

Table 3: Parameters tested and relevant simulation ID

\begin{tabular}{|c|c|c|}
\hline Variable & Values/Method & Sim ID \\
\hline $\begin{array}{c}\text { Sim starting } \\
\text { day }\end{array}$ & $4^{\text {th }}$ of August & $01-03$ \\
$5^{\text {th }}$ of August & $04-12$ \\
\hline Air Temp & $22.0^{*}$ (Heathrow) & 01 \\
$\left({ }^{\circ} \mathrm{C}\right)$ & $23.8^{*}$ (Measurements) & $02-11$ \\
& $22.7^{*}$ (UWG) & 12 \\
\hline Wind speed & 4.0 (Heathrow $)$ & - \\
$(\mathrm{m} / \mathrm{s})$ & 2.0 (K. \& G. method) & $01-03$ \\
& 1.4 K. \& G. method) & 04 \\
& 2.5 (BS 5925:1991) & $05-12$ \\
\hline Buffer time & 48 & 06 \\
(hours) & 24 & $01-05 ; 07-12$ \\
\hline Rad fluxes & IVS On & 07 \\
(sim. method) & IVS OFF & $01-06 ; 08-12$ \\
\hline Area size & $200 x 200 x 60$ & $01-07 ; 10-12$ \\
(m) & $500 x 300 x 80$ & $08-09$ \\
\hline Materials of & Single material & $01-02 ; 08 ; 10$ \\
wall and roof & Individual materials & $03-07 ; 09 ; 11 ; 12$ \\
\hline
\end{tabular}

* mean value of the hourly data used for simple forcing

Table 4: Accuracy of ENVI-met air temperature estimations at $5 \mathrm{~m}$ height

\begin{tabular}{|c|c|c|c|c|}
\hline Sim ID & RMSE & MAE & d & $\begin{array}{c}\text { R } \\
\text { squared }\end{array}$ \\
\hline S_01 & 5.42 & -5.19 & 0.74 & 0.95 \\
\hline S_02 & 4.38 & -4.19 & 0.81 & 0.96 \\
\hline S_03 & 3.51 & -3.20 & 0.86 & 0.96 \\
\hline S_04 & 1.45 & -1.17 & 0.97 & 0.99 \\
\hline S_05 & 1.29 & -0.86 & 0.98 & 0.99 \\
\hline S_06 & 1.41 & -0.99 & 0.98 & 0.99 \\
\hline S_07 & 1.44 & -1.11 & 0.97 & 0.99 \\
\hline S_08 & 1.41 & -0.78 & 0.97 & 0.99 \\
\hline S_09 & 1.66 & 0.48 & 0.96 & 0.98 \\
\hline S_10 & 1.15 & 0.48 & 0.98 & 0.99 \\
\hline S_11 & 1.33 & -0.42 & 0.98 & 0.97 \\
\hline
\end{tabular}

The results also show that ENVI-met provides much more reliable results when local air temperatures (S02) instead of airport data (S10) are used to force the simulation. When the meteorological input settings are well chosen, the RMSE variability strongly decreases (S04-S12). Both measured local air temperatures (S04-S11) and estimations using urban energy balance models such as UWG (S12) proved to be suitable input data.

As for the wind speed, the power law given by the BS 5925:1991 provides better accuracy than the coefficients given by Kofoed \& Gaardsted to estimate the wind speed attenuation due to the urban roughness. However, using the two methods, the RMSE change was minimal, from $1.45^{\circ} \mathrm{C}$ in S04 to $1.29^{\circ} \mathrm{C}$ in S05. Furthermore, wind speed measurements would be necessary to validate this input parameter.
The impact of the other input parameters on the air temperature estimations is much less significant than the meteorological settings. This is shown in Figure 3, which represents just the results of the simulations forced with local air temperature of the same day of comparison. The RMSE variation determined by the size of the model and the material distribution is between $1.45^{\circ} \mathrm{C}$ and $1.15^{\circ} \mathrm{C}$.

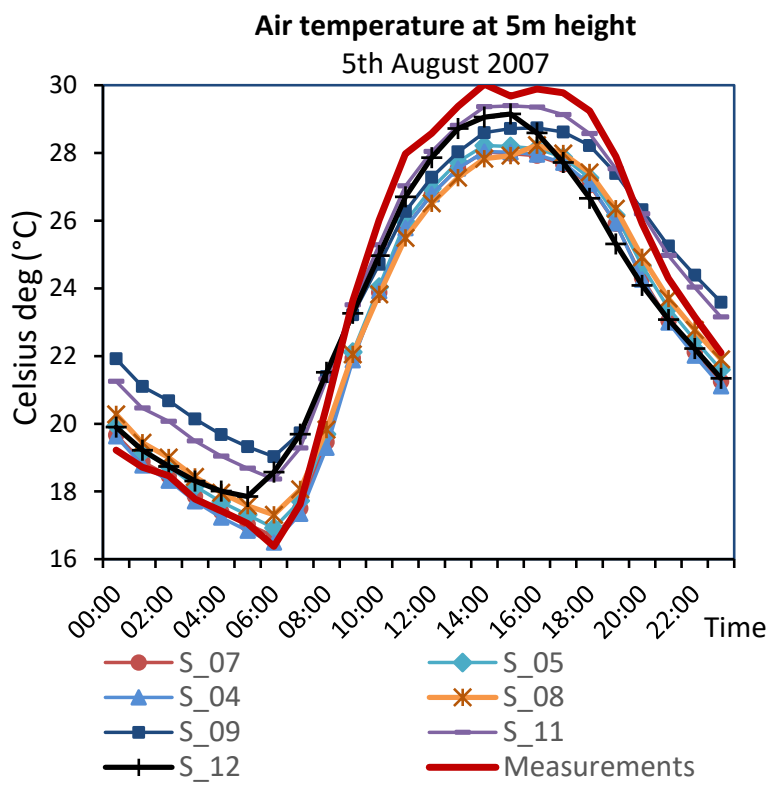

Figure 3: Comparison of the modelled and measured diurnal cycles of air temperature at $5 \mathrm{~m}$ height of the simulations forced with the meteorological conditions of the same day of comparison, considering $24 \mathrm{hrs}$ buffer time

The area size determines significant changes in the wind field (speed and direction) which affect air temperature estimations. According to this study, the results are more accurate for small areas (about 200mx200m) than large areas $(300 \times 500 \mathrm{~m})$. The simulation performed with the large model, with detailed material specifications and using local air temperatures as input, resulted in a significant overestimation of the air temperature during the night time (S09 in Figure 3). This probably happens because of an overestimation of the urban effect. One time, due to the significant reduction of the wind speed in the big model compared to the small model. The second time, due to the use of the local air temperatures as input, which already embed the air temperature increase determined by the characteristics of the urban fabric, including the wind speed decrease (Salvati et al. 2016 \& 2017, Kolokotroni et al. 2008).

The impact of the detailed distribution of the materials of facades and roof varies depending on other input parameters. The large model was simulated using the same material for roof and walls (S08 - material reflectivity 0.3 ) and with a detailed distribution of materials (S09); in this case, the RMSE increased from $1.42{ }^{\circ} \mathrm{C}$ (S08) to $1.66{ }^{\circ} \mathrm{C}$ (S09), which can be explained by a redundant computation of the urban effect, as previously commented. Conversely, with small input areas, the specification of materials increases the accuracy 
of the estimation, but the impact varies depending on the reflectivity chosen for the uniform material and the input wind speed. For example, the specification of materials in S03 (wind speed $2 \mathrm{~m} / \mathrm{s}$ ), determined a decrease of the RMSE of almost $1{ }^{\circ} \mathrm{C}$ compared to S02. However, for higher wind speed $(2.5 \mathrm{~m} / \mathrm{s})$ and for albedo values of the uniform material closer to the actual ones, the difference in RMSE is much lower. In fact, the RMSE only varied from $1.16^{\circ} \mathrm{C}$ to $1.15^{\circ} \mathrm{C}$ between $\mathrm{S} 10$ in $\mathrm{S} 11$, where $\mathrm{S} 11$ has the detail distribution of materials (Figure 2c and Table 2) and S10 uniform materials for walls and roof, set to clear shingles $(r=0.14)$ and red brick $(r=0.32)$. However, the materials of facades and roofs do have an impact on the distribution of surface temperatures.

Finally, the use of the IVS method did not improve the accuracy of air temperature estimations. It had a significant impact on the radiation balances within the canyon, but at the cost of an extremely longer computation time: the simulation with a super computer lasted about 120 hours versus 38 hours without IVS.

Similarly, the consideration of a buffer time longer than 24 hours did not changed the results.

Among the set of simulations, the best accuracy was achieved by S10, with a RMSE of $1.15{ }^{\circ} \mathrm{C}$. This corresponds to an input area of about $200 \times 200 \mathrm{~m}$, with detailed specification of facades and roofs materials, using as forcing conditions the site temperature measurements and the BS5925:1990 for wind speed attenuation from airport data. It has to be highlighted that all the simulations underestimated the air temperature during daytime. The results of S_10 provided the best approximation during daytime, but also a slight overestimation of the nighttime temperature.

\section{Microclimate variations across the calibrated model}

The results also confirmed that the variations of the climate variables across the $200 \times 200 \mathrm{~m}$ domain are significant in terms of wind speed and mean radiant temperature, while they are not in terms of air temperature. The graphs in figure 5 show the diurnal cycle of these variables at $5 \mathrm{~m}$ height across the different receptors placed in the model as represented in Figure 4.

The first graph in Figure 5 shows that the air temperature at $5 \mathrm{~m}$ height is almost the same across the different receptors of the model, throughout the day. The maximum relative difference is around $0.55^{\circ} \mathrm{C}$ and occurs between 11:00 and 14:00, between the point L5 (hotter) and points $\mathrm{K} 1$ and K2 (colder). This probably happens because the surfaces around point L5 receive much more radiation over the morning compared to $\mathrm{K} 1$ and $\mathrm{K} 2$, due to geometry and orientation; L2 is not in an urban canyon as opposite to $\mathrm{K} 1$ and $\mathrm{K} 2$ and it faces a south-east oriented façade. However, the difference in terms of air temperature is not significant. Closer to the ground level, the diurnal air temperature differences are slightly higher: at $1.8 \mathrm{~m}$ agl, the maximum relative difference reached 0.73 ${ }^{\circ} \mathrm{C}$ at 14:00, between the points L5 and C2. Conversely, wind speed variations are significant across the model, with differences up to $1 \mathrm{~m} / \mathrm{s}$ in very short distances, such as between the points $\mathrm{S} 4$ and $\mathrm{C} 2$, where the maximum and minimum speeds are estimated respectively.

Also the mean radiant temperature varies significantly across the model. The maximum relative difference over the day reached $30.9{ }^{\circ} \mathrm{C}$ at $16: 00$ and occurred between point L2 $\left(63.7^{\circ} \mathrm{C}\right)$ and $\mathrm{C} 2\left(32.8{ }^{\circ} \mathrm{C}\right)$, the latter being located under one tree.

As for the façade temperature, the maximum differences were found on the south-west oriented facades, due to the higher impact of solar radiation. The temperature difference on the south-west facades reached up to $30^{\circ} \mathrm{C}$ at 15:00, between the irradiated portion painted in dark green and the shadowed portion in bricks. However, the temperature difference between the same two points dramatically decreased to about $2{ }^{\circ} \mathrm{C}$ at 19:00, due to the beneficial effect of shadows on the dark green surface.

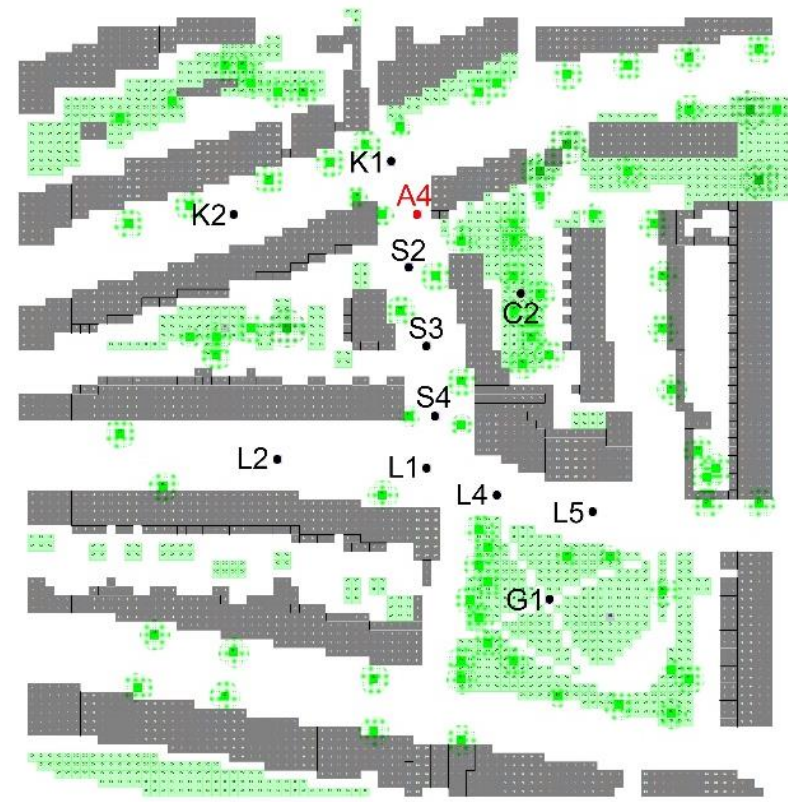

Figure 4: Location of the 12 receptors in the model, where point A4 corresponds to the location of the site temperature sensor

Both the surface temperatures and the mean radiant temperatures are driven by the amount of direct solar radiation received by the surfaces and, therefore, by the surrounding urban geometry and facades orientation.

This is clear also from the results for the Predicted Mean Vote (PMV) reported in Figure 7. The PMV is a thermal index developed by Fanger (1982) to assess indoor thermal comfort. The PMV calculated by ENVI-met has been adapted for outdoor conditions, including solar radiation and wind speed. In an indoor environment, the PMV normally varies between -4 and +4 , where zero means thermally neutral, -4 means very cold and +4 very hot. The PMV was developed based on experiments on indoor environments and its use for outdoors is not fully reliable. Furthermore, it has been known that the physiological approach alone is not sufficient to characterise human thermal comfort in outdoor environments (Nikolopoulou, 2001). Therefore, the PMV is used in this study just to highlight the variability of the 
thermal environment across the study area, as resulting by the combination of solar radiation, wind speed, air temperature and surface temperatures.
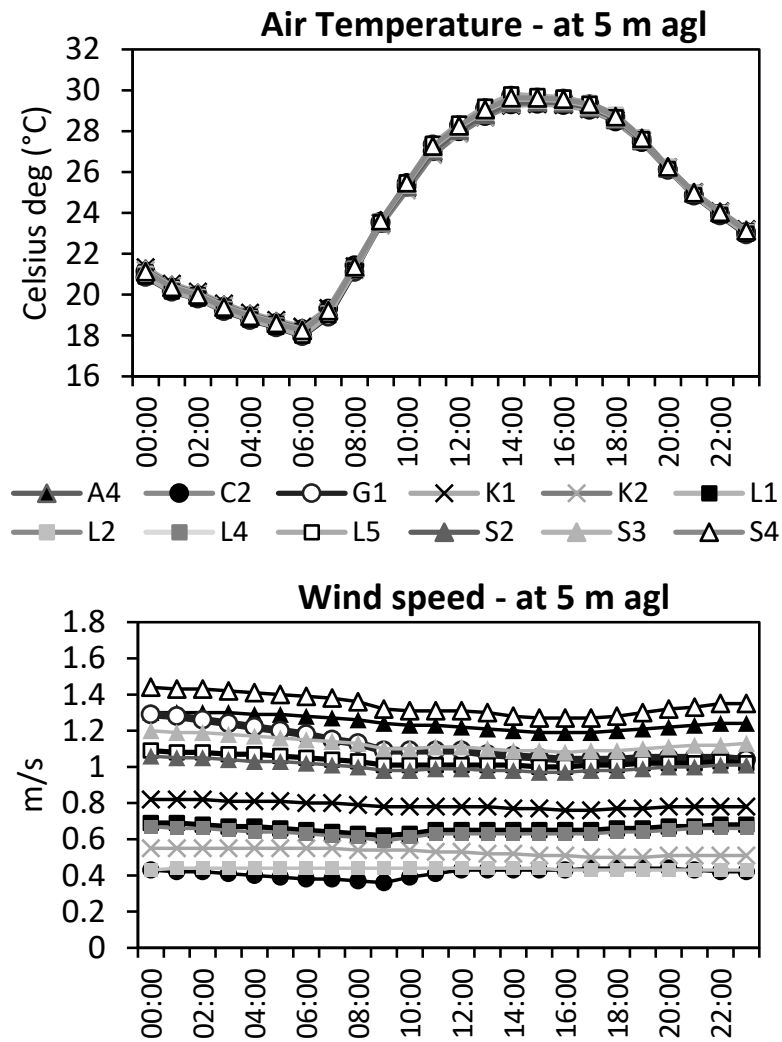

$\rightarrow \mathrm{A} 4 \rightarrow \mathrm{C} 2 \rightarrow \mathrm{G} 1 \rightarrow \mathrm{K} 1 \rightarrow \mathrm{K} 2 \rightarrow-\mathrm{L} 1$
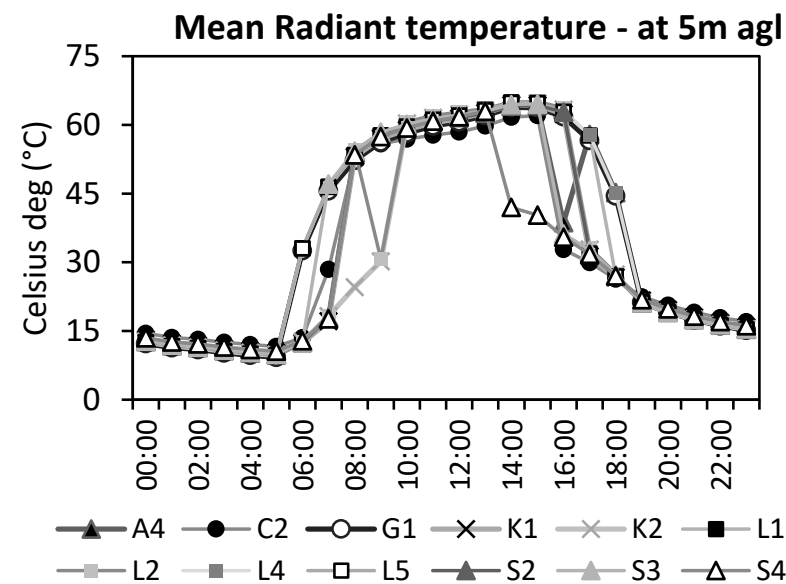

Figure 5:Diurnal cycle of air temperature, wind speed and mean radiant temperature at the 12 model receptors

The results reported in figure 7 show that the risk of heat stress is very high everywhere in the area at 15:00. Two thermal environments can be identified: one 'very hot', where direct solar radiation is present (PMV above 4) and one 'warm-to- hot', in the shadowed areas (PMV between 2 and 2.5).

In light of this, it can be argued that the most significant difference is determined by the shadows from trees and buildings. Within the boundaries of this simulation, no significant variations in the thermal environment are determined by individual materials of buildings and roads or wind speeds (air temperature is uniform).

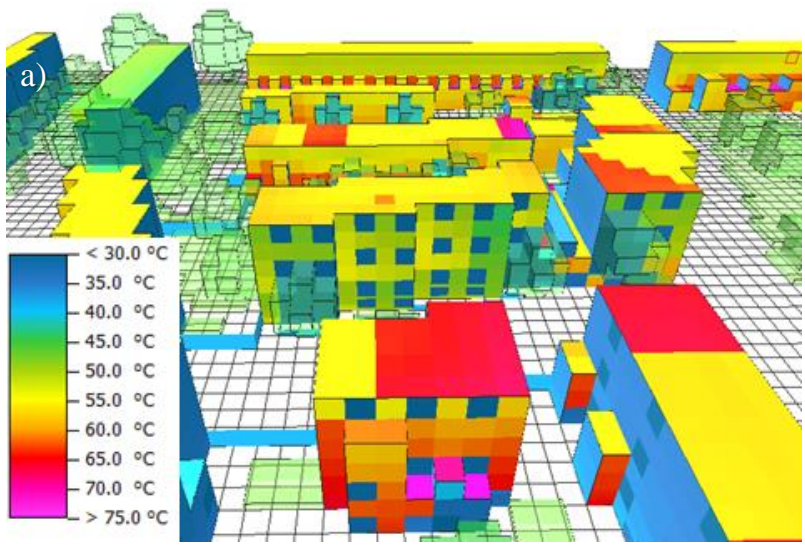

b)

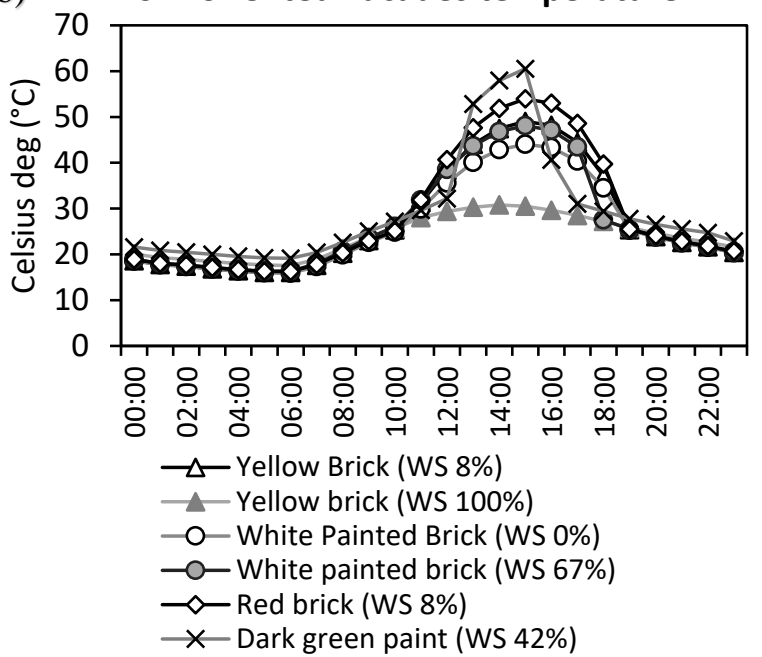

Figure 6: a) Spatial distribution of temperature on $\mathrm{SW}$ oriented façades on the $5^{\text {th }}$ August 2007 at 15:00 and b) hourly façade temperature for different materials and percentage of time in shadow (WS)

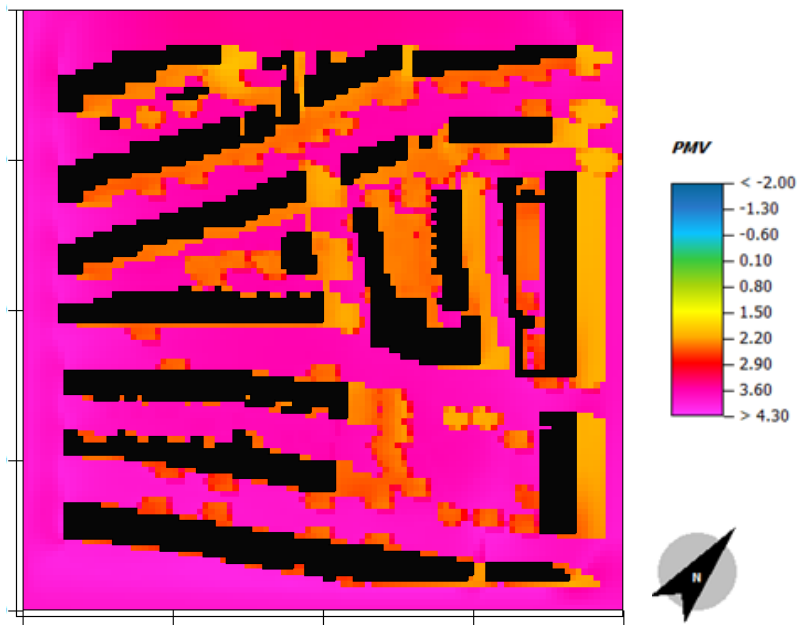

Figure 7: Predicted mean vote (PMV) across the model at 15:00 of 5th of August 2007, at $1 \mathrm{~m} \mathrm{agl.}$

\section{Discussion}

The results presented allow understanding which tools and scale of analysis are more suitable to derive representative boundary conditions for building energy 
modelling considering the climate modifications determined by built environments (Kolokotroni et al 2008, Palme et al 2018, Salvati et al 2017a).

As regard urban air temperature, UWG can be used to estimate the local urban heat island effect for building energy simulation purposes. The detailed ENVI-met simulations showed negligible horizontal and vertical thermal gradients within the microscale.

On the other hand, ENVI-met simulations confirmed that significant variations in the incoming solar radiation, wind speed and surface temperature occur at the microscale. The possibility to include these phenomena in building performance modelling comes with more or less difficulty depending on the phenomenon. For example, the variability of solar gains and daylight in an urban environment can be estimated also with less sophisticated tools than CFD, such as thermal comfort models (i.e. RAYMAN, Matzarakis et al. 2007), building energy models (i.e. EnergyPlus, US Department of Energy 2015) or solar energy models (i.e. Heliodon2, Beckers \& Masset 2011). Compared to these, ENVI-met allows a more detailed calculation of the multiple reflections in the urban canyon using the IVS model. However, this comes at the cost of a huge computational time and its impact on the energy performance of buildings is to be investigated. CFD tools are instead necessary to model the wind field and the consequent convective effects on surface temperatures.

The impact of wind speed, surface temperature, air temperature and solar radiation on buildings energy demand may have different relative weights depending on the geographic and topographic location and the characteristics of the urban fabric. In fact, the relative weight of air temperature and solar radiation has been found to depend on urban morphology and building typology at lower latitudes (Palme \& Salvati 2018b). Also, the wind flow variation across an urban area depends on geometry and orientation of urban canyons and mean wind speed above the canopy layer (Georgakis et al. 2012, Nardecchia et al. 2018).

This means that the relative impact of the different urban microclimate variables on building energy demand has to be further investigated in order to understand in which situation a detailed CFD simulation is necessary to obtain reliable energy estimations for urban buildings.

\section{Conclusion}

The results of this study leads to the following conclusions regarding the accuracy of ENVI-met simulations:

- Among the tested parameters, the meteorological settings have the largest impact on microclimate results. An informed choice of the meteorlogical intial conditions is crucial to obtain reliable results.

- ENVI-met results are reliable only for the day(s) of the forcing conditions. If the microclimate analysis is targeted to one specific day, the meteorological conditions of that day must be used as forcing data.
Longer meteorlogical periods can be set to force the simulation with the last software releases (V 4.4.).

- Local hourly air temperature should be used as meteorological forcing conditions. These can be either measured on site or generated with a validated urban energy balance model, such as the Urban Weather Generator tool.

- The input urban wind speed can be estimated from airport data using the power law in BS 5925:1991

- The size of the model significantly affects canyon wind speed and air temperature. If local weather data are used as forcing conditions, small areas should be simulated. In this study, an area size of $200 \times 200 \mathrm{~m}$ worked well.

- The detailed specification of materials has less impact than the meteorological settings, but it is has a rather significant impact on the distribution of surface temperatures and mean radiant temperatures.

- The radiation fluxes vary significantly using the new IVS algoritm but the impact on air temperature is not significant

The analyses of the microclimate variation across the calibrated model also suggest that air temperature can be considered uniform over microscale domains, while wind speed and solar radiation are likely to vary significantly, affecting surface temperatures and mean radiant temperatures. Therefore, CFD results are necessary to estimate the natural ventilation potential and the impact of the infrared environment on the energy demand of urban buildings.

In this study, ENVI-met was calibrated for the hottest day of the observation period, using 24 hours of measured air temperature data. In the next developments of the research, the last release of the software will be used and calibrated for longer meteorological periods using full forcing; furthermore, the accuracy of radiation balance calculation will be assessed against measured radiation data.

\section{Acknowledgement}

This work was funded by EPSRC under the project 'Urban albedo computation in high latitude locations: An experimental approach' (EP/P02517X/1).

\section{References}

Beckers, B., \& Masset, L. (2011). Heliodon2 documentation. Retrieved from www.heliodon.net

British Standards Institution (1991). Code of practice for ventilation principles and designing for natural ventilation (BS 5925:1991)

Bruse, M. (2018). ENVI-met Technical model webpage, http://www.envi-met.info/doku.php?id=start

Bueno, B., Norford, L., Hidalgo, J., \& Pigeon, G. (2013). The urban weather generator. Journal of Building Performance Simulation, 6(4), 269-281.

Duarte, D. H. S., Shinzato, P., Gusson, C. dos S., \& Alves, C. A. (2015). The impact of vegetation on urban microclimate to counterbalance built density in a 
subtropical changing climate. Urban Climate, 14, 224-239.

Fanger, P. O. (1982). Thermal Comfort. Analysis and Application in Environment Engineering. McGraw Hill Book Company, New York.

Georgakis, C., \& Santamouris, M. (2012). Wind and Temperature in the Urban Environment. In F. Allard \& C. Ghiaus (Eds.), Natural Ventilation in the Urban Environment: Assessment and Design. Routledge. London (UK).

Goldber, V., Kurbjuhn, C., \& Bernhofer, C. (2013). How relevant is urban planning for the thermal comfort of pedestrians? Numerical case studies in two districts of the City of Dresden (Saxony/Germany). Meteorologische Zeitschrift, 22(6), 739-751.

Kofoed, N.-U., \& Gaardsted, M. (2004). Considerations of the Wind in Urban Spaces. In M. Nikolopoulou (Ed.), Designing open spaces in the urban environment: a bioclimatic approach rediscovering the urban realm and open spaces, key action 4 "City of tomorrow and cultural Heritage" from the programme "Energy, Environment and Sustainable Development”. Centre for Renewable Energy Sources (C.R.E.S.), Greece

Kolokotroni, M., \& Giridharan, R. (2008). Urban heat island intensity in London: An investigation of the impact of physical characteristics on changes in outdoor air temperature during summer. Solar Energy 82(11), 986-998.

Kolokotroni, M., Giannitsaris, I., \& Watkins, R. (2006). The effect of the London urban heat island on building summer cooling demand and night ventilation strategies. Solar Energy, 80(4), 383-392.

Kotthaus, S., Smith, T. E. L., Wooster, M. J., \& Grimmond, C. S. B. (2014). Derivation of an urban materials spectral library through emittance and reflectance spectroscopy. ISPRS Journal of Photogrammetry and Remote Sensing, 94, 194-212.

Lindberg, F., Grimmond, C. S. B., Gabey, A., Huang, B., Kent, C. W., Sun, T., ... Zhang, Z. (2018). Urban Multi-scale Environmental Predictor (UMEP): An integrated tool for city-based climate services. Environmental Modelling and Software, 99, 70-87.

Mao, J. (2018). Automatic calibration of an urban microclimate model under uncertainty. MSc thesis, Massachusetts Institute of Technology.

Matzarakis, Andreas, Frank Rutz, and Helmut Mayer. 2007. "Modelling Radiation Fluxes in Simple and Complex Environments--Application of the RayMan
Model." International Journal of Biometeorology 51 (4): 323-34.

Nardecchia, F., Bernardino, A. Di, Pagliaro, F., Monti, P., Leuzzi, G., \& Gugliermetti, L. (2018). CFD Analysis of Urban Canopy Flows Employing the V2F Model : Impact of Different Aspect Ratios and Relative Heights. Advances in Meteorology, 2018, Article ID 2189234.

Nikolopoulou, M., Baker, N., \& Steemers, K. (2001). Thermal comfort in outdoor urban spaces: Understanding the Human parameter. Solar Energy, 70(3), 227-235.

Oke, T. R., Mills, G., Christen, A., \& Voogt, J. A. (2017). Urban Climates. Cambridge University Press. Cambridge (UK)

Palme, M., Inostroza, L., \& Salvati, A. (2018a). Technomass and cooling demand in South America: a superlinear relationship? Building Research \& Information 46, 864-880.

Palme, M., \& Salvati, A. (2018b). UWG -TRNSYS Simulation Coupling for Urban Building Energy Modelling. In Proceedings of BSO 2018: 4th Building Simulation and Optimization Conference, Cambridge, UK: 11-12 September 2018 (pp. 635-641).

Salata, F., Golasi, I., de Lieto Vollaro, R., \& de Lieto Vollaro, A. (2016). Urban microclimate and outdoor thermal comfort. A proper procedure to fit ENVI-met simulation outputs to experimental data. Sustainable Cities and Society 26, 318-343.

Salvati, A., Coch, H., \& Cecere, C. (2016). Urban Heat Island Prediction in the Mediterranean Context: an evaluation of the urban weather generator model. ACE: Architecture, City and Environment = Arquitectura, Ciudad Y Entorno, 11(32), 135-156.

Salvati, A., Coch, H., \& Cecere, C. (2017a). Assessing the urban heat island and its energy impact on residential buildings in Mediterranean climate: Barcelona case study. Energy and Buildings, 146, 38-54. http://doi.org/10.1016/j.enbuild.2017.04.025

Salvati, A., Palme, M., \& Inostroza, L. (2017b). Key Parameters for Urban Heat Island Assessment in A Mediterranean Context: A Sensitivity Analysis Using the Urban Weather Generator Model. IOP Conference Series: Materials Science and Engineering 245, 82055.

Stewart, I. D., \& Oke, T. R. (2012). Local Climate Zones for Urban Temperature Studies. Bulletin of the American Meteorological Society 93(12), 1879-1900.

US Department of Energy. (2015). Engineering reference The Reference to EnergyPlus Calculations. 